\title{
Persistence of UK Real Estate Returns: A Markov Chain Analysis
}

\author{
S. L. Lee and C.W.R. Ward ${ }^{1}$ \\ Department of Land Management, The University of Reading \\ Whiteknights, Reading, RG6 6AW, England \\ Phone: +44 (0) 118931 6338, Fax: +44 (0) 118931 8172, E-mail: c.ward@ reading.ac.uk
}

October 2000

Keywords: Real Estate Returns, Persistence, Markov Chains, Trading Strategy.

\begin{abstract}
The persistence of investment performance is a topic of perennial interest to investors. Efficient Markets theory tells us that past performance can not be used to predict future performance yet investors appear to be influenced by the historical performance in making their investment allocation decisions. The problem has been of particular interest to investors in real estate; not least because reported returns from investment in real estate are serially correlated thus implying some persistence in investment performance.

This paper applies the established approach of Markov Chain analysis to investigate the relationship between past and present performance of UK real estate over the period 1981 to 1996 . The data are analysed by sector, region and size. Furthermore some variations in investment performance classification are reported and the results are shown to be robust.
\end{abstract}

\footnotetext{
${ }^{1}$ Author to whom correspondence should be addressed
} 


\section{Introduction}

It is hard for investors to use past information about the behaviour of stock and other asset prices to predict future performance, see Fama (1970) and LeRoy (1982). Yet it seems to be compelling for most investors to purchase investments that have performed well in the past and sell investments that have performed poorly. In apparent support of this sentiment empirical evidence indicates that security returns may be predictable over short horizons (Grinblatt and Titman, 1989, 1992, Hendricks et al., 1993, Malkiel, 1995, Goetzmann and Ibbotson, 1994, Brown and Goetzmann, 1995). Moreover, as one moves from the well traded and liquid markets for stocks and bonds into the real estate market, several empirical studies suggest that real estate returns are even more persistent over a number of years, see Young and Graff $(1996,1997)$ and Graff, Harrington and Young (1999).

The viability of an investment strategy based on persistence depends upon the stability and strength of the successive period performance relationship. Consequently it is important to determine whether the best-performing investments in the past are likely to be the best-performing investments in the future. In other words, do winners repeat?

The purpose of this study is to investigate the extent and implications of serial persistence in the UK real estate market. The approach adopted here is to model the dynamics of real estate returns through time by a Markov chain process that allows the estimation of several parameters of interest not readily available from other types of analysis.

The paper is organised as follows: the following section reviews the previous research into the persistence of real estate returns. Section 3 outlines the methodology used in 
investigating persistence. Section 4 then describes the data and presents the results. Section 5 concludes the study.

\section{Previous Studies}

Serial persistence in real estate returns has been examined in the direct real estate markets in the USA (Young and Graff, 1996, 1997), Australia (Graff, Harrington and Young, 1999) and in the USA indirect real estate market (using stock price returns from Real Estate Investment Trusts, REITs), Graff and Young (1997). The approach adopted for testing for persistence was the same in each case. For each time period the total returns of each property, or REIT, was calculated and the return ranked into quartiles. The use of quartile ranks implied that if the performance of real estate returns through time is independent there was a $25 \%$ probability of remaining in the same quartile from one period to the next. Consequently a significant departure from the $25 \%$ theoretical probability could be considered as an indicator of serial dependence in performance.

The analysis for the US (Young and Graff, 1996, 1997) used annual returns from the NCREIF database, over the period 1978 to 1994 . The study based on the return performance of fifty Metropolitan Standard Areas (MSAs) that had at least one occurrence of two consecutive years of data, the total number of MSAs ranging from eight in 1978 to forty-four in 1991. The data was also decomposed into the five property types: Office, Retail, Warehouse, R\&D and Apartments. The results for the five property types indicating that for the two extreme quartiles, the highest and lowest ranks, serial persistence was demonstrated with almost complete certainty from one year to the next. Although the persistence tended to weaken beyond this, the performance of Apartments exhibited serial persistence extending to runs of two and three years. For 
the combined data serial persistence was exhibited for one, two, three, four and five years, indicating that private real estate returns exhibit persistence for some considerable time. In contrast little or no significant serial persistence was found for the second and third quartiles, except for Warehouses over one year and the combined data for one- and two- years runs. In other words persistence is exhibited at the extremes of performance, the best and the worst properties, in any one year but not by properties around the median.

The Australian study (Graff, Harrington and Young, 1999) used annual data over the period from 1985 to 1997 from the Property Council of Australia database. The data were decomposed into the three property types: Office, Retail and Industrials. The results of the analysis showed that serial persistence was exhibited by Office and Retail property at the extreme quartiles (the first and fourth) and for the median quartiles (second and third combined), but that Industrial properties exhibited serial independence in all categories. In addition there was a qualitative difference in the Office data between Central Business District (CBD) and non-CBD properties. In particular the Office data in the CBD locations exhibited serial persistence in all quartiles but no serial persistence was found for the non-CBD data. The combined data exhibited statistically significant results in all quartiles. In other words superior performance was generally followed by continued superior performance and inferior performance by continued inferior performance.

Finally, using monthly, quarterly and annual data over the ten-year period from January 1987 to December 1996, Graff and Young (1997) found that the results for REITS were somewhat different. In particular the data showed a variety of conclusions depending on the sample frequency. For the annual data, like the results for the private real estate 
market, persistence was observed at the two extremes (i.e. combined first and fourth quartiles) while the two moderate quartiles (i.e. combined two and three quartiles) were statistically insignificant from the theoretical $25 \%$ probability. In contrast the quarterly data showed a lack of serial persistence in the extreme and the moderate quartiles. The monthly returns displayed yet different results, with the extreme quartiles showing negative persistence. That is, REITs in the fourth and the first quartile had less than a $25 \%$ chance of being in those quartiles in the subsequent period. The negative persistence was more pronounced for large capitalised REITs that for small capitalised REITs.

The existence of such persistence in real estate returns would seem to imply some market inefficiency. Some might argue that persistence in real estate returns results from the way total returns are calculated from appraisal based valuations and the serial persistence that this imparts to returns through time; an argument rejected by Graff, Harrington and Young (1999). Others would suggest that the real estate markets are inefficient due to high search and transaction costs involved in the purchasing and selling of property. Given this condition, the fact that there is persistence in performance of individual properties could not be exploited and the efficient market hypothesis would not be invalidated.

A serious inference drawn by Young and Graff (1996) is that any persistence in performance casts doubt on the application of formal portfolio construction techniques used in real estate markets based on mean-variance analysis since such models rely on a risk proxy, the standard deviation of returns to be i.i.d. (independently and identically distributed). The findings of Myer and Webb (1990, 1993), Young and Graff (1996) and Byrne and Lee (1997) that real estate returns are not normally distributed would confirm 
this argument. Graff, Harrington and Young (1999) claim that research based upon models that incorporate the assumption of independence is of questionable value to real estate investors.

The question of the non-normality of real estate data is probably not a major issue as portfolio models need not be based on mean-variance analysis. Alternatives including models based on various lower partial moments (LPM), especially mean semi-variance, and portfolio approaches that use mean absolute deviation (MAD), both of which have been applied to real estate markets, see Byrne and Lee (1997) and Sivitanides (1998). The persistence of serial persistence in returns, however, does raise more general concerns about the efficiency of the markets.

\section{Data and Methodology}

\subsection{Data}

The data are derived principally from the Local Markets Report (IPD, 1998). The data in the Local Markets Report are in turn drawn from a total database of 13,721 properties with an aggregate value of $£ 65,394 \mathrm{~m}$ at the end of 1997 . The sample data consist of the total returns on properties in three sectors, Retail, Office and Industrial at various locations in the UK over the period 1981 to 1996, to give a total of 392 asset possibilities. To protect confidentiality no data are published for locations containing fewer than four properties in any year. The locations are based for the most part on local authority boundaries drawn up in the 1992 Local Government Act. As a result asset descriptions might be, for example, 'Manchester Retail', or 'Westminster Offices' or 'Walsall Industrial'. For Offices and Industrials the Local Markets Report results 
are based on all Offices and Industrial properties covered by IPD in each location. For Retails, given the distinction that have arisen with the advent of retail warehouses only standard shops in each location, are covered in order to provide a sample on a comparable basis. In terms of coverage the Retail data represent over $95 \%$ of all Standard shops covered by the IPD database. The comparable figures for Offices and Industrial are $72 \%$ and $70 \%$ respectively. The Local Markets Report data consequently forms a very representative coverage of commercial property in the UK.

The Local Markets Report data are also classified into the Standard Regions of the UK but with the South East subdivided into London and the Rest of the South East because London represents a dominant area of institutional property investment. As a consequence a number of the regions have only a few data points. In order to have enough data points to conduct the analysis these regions were amalgamated into larger contiguous, areas. The South West, East Anglia, the East and West Midlands were amalgamated, with Wales, to form a South and West region. The Yorkshire and Humberside region was combined with the North West, the North, and Scotland to form a Northern region. Table 1 summaries the resulting property sector and regional breakdown of the data.

\section{TABLE 1 ABOUT HERE}

Although the data represent portfolios, for simplicity in this paper we will refer to the data point as a "property".

\subsection{Markov Chains}


The movements of properties or funds between quartiles suggest a stochastic process. Of the range of stochastic models, those based on the Markov process, and in particular the Markov chain model, seem most suitable to describe and predict property performance rankings over time. The concept of Markov process was introduced around 1907, but did not come into general use till the 1970s. The process assumes that if any population of properties can be classified into various groups or "states" that movements of properties between states over time can be regarded as a stochastic process. With a given set of states $\left(\mathrm{S}_{1}, \mathrm{~S}_{2}, \ldots \ldots \mathrm{S}_{\mathrm{n}}\right)$, it is assumed possible to estimate the probabilities $\left(\mathrm{p}_{\mathrm{ij}}\right.$ ) of properties moving from $\mathrm{S}_{\mathrm{i}}$ to $\mathrm{S}_{\mathrm{j}}$.

In particular the Markov process is based on the assumption that the probabilities that any state $\mathrm{S}$ will occur in a time sequence at $t$ is dependent upon the state of the system at $t-1$ and independent of all other states. The transition between the state of the system at $t-1$ and the state of the system at $t$ can be therefore mathematically described as a set of probabilities arrayed in matrix form. Thus the quartile distribution of properties, in say 1982 is some function of their distribution at say 1981 modified by some component of change that covers the intervening period.

The Markov chain is one type of Markov process, conforming to the same basic set of assumptions, but with the additional property that any state $S$ occurring at time $t$ in a particular sequence $t$, is independent of its position in that sequence. A Markov chain is therefore a Markov process with the added assumption of stationarity. That is the matrix of transitional probabilities does not change from one time period to the next. Thus the Markov process needs to be tested for stationarity before it can be regarded as a Markov chain, this is done below. 
These probabilities of movements during a time period can be expressed in the form of a square transition probability matrix $(\mathrm{P})$ with the form:

$$
\left[\begin{array}{llll}
\mathrm{p}_{1,1} & \mathrm{p}_{1,2} & \mathrm{p}_{1,3} & \mathrm{p}_{1,4} \\
\mathrm{p}_{2,1} & \mathrm{p}_{2,2} & \mathrm{p}_{2,3} & \mathrm{p}_{2,4} \\
\mathrm{p}_{3,1} & \mathrm{p}_{3,2} & \mathrm{p}_{3,3} & \mathrm{p}_{3,4} \\
\mathrm{p}_{4,1} & \mathrm{p}_{4,2} & \mathrm{p}_{4,3} & \mathrm{p}_{4,4}
\end{array}\right]
$$

The value $\mathrm{P}_{2,2}$ in the matrix represents the probability that a property in the second quartile ranking at time $t$ will remain in the second quartile ranking at $t+1$ (Kemeny and Snell 1960). The value $P_{1,2}$ in the matrix represents the probability that a property in the first quartile ranking at time period $t$ will move to the second quartile in period $t+1$. That is, the probabilities to the right of the diagonal indicate the likelihood of a property moving to a lower quartile ranking and to the left of the diagonal the probability of a property moving to a higher quartile.

Two tests are then performed on the transition matrix. First a test of stationarity and second a test of persistence. To test the assumption of stationarity Anderson and Goodman (1957) have shown that the maximum likelihood estimates of the stationary transition probabilities are:

$$
p_{i j t}=\frac{\sum_{t=1}^{T} m_{i j t}}{\sum_{j=1}^{n} \sum_{t=1}^{T} m_{i j t}}
$$

where $\mathrm{p}_{\mathrm{ijt}}$ is the transition probability that the property will move from state $\mathrm{i}$ to state $\mathrm{j}$ in time period t, estimated by calculating the number of movements $(\mathrm{m})$ of properties from 
state $\mathrm{i}$ into state $\mathrm{j}$ in time period $\mathrm{t}$. The number of movements $(\mathrm{m})$ calculated by finding the quartile rank of each property at time period $t$ and comparing this with its quartile rank at time period $t+1$. Accordingly if property $\mathrm{i}$ changed its ranking this is counted as a movement. The sum of all movements between quartile ranks $i$ and $j$ are then aggregated and divided by the total sum of movements across all quartile ranks. Given the estimates, $\mathrm{p}_{\mathrm{ijt}}$, it is possible to test the null hypothesis that the true transition probabilities are stationary. The test statistic is:

$$
-2 \log \lambda=2\left[\sum_{\mathrm{i}=1}^{\mathrm{n}} \sum_{\mathrm{j}=1}^{\mathrm{n}} \sum_{\mathrm{t}=1}^{\mathrm{T}} \mathrm{m}_{\mathrm{ijt}} \log \mathrm{p}_{\mathrm{ijt}}-\sum_{\mathrm{i}=1}^{\mathrm{n}} \sum_{\mathrm{j}=1}^{\mathrm{n}} \sum_{\mathrm{t}=1}^{\mathrm{T}} \mathrm{m}_{\mathrm{ijt}} \log \mathrm{p}_{\mathrm{ij}}\right]
$$

The statistic distributed as a Chi-square statistic with $[(\mathrm{t}-1) *(\mathrm{n}-1)]$ degrees of freedom. In this test, the sample set is divided into sub-periods. The number of sub-divisions is a compromise between the number of observations and the fineness of the test. If for example, each period is used as a sub-sample, there will be many different estimates but we will have little confidence in the estimated transition probability matrices. The fewer the number of sub-periods, the more confident we will be that the transition probabilities are correctly estimated but the test for stability will be less sensitive. After some trials, the data was divided into four sub-samples for the purpose of testing for stability.

After establishing that the data sets are stable, the next stage is to test whether there is any persistence. If the system had no pattern or persistence from one state to another, we would expect to see that $\mathrm{p}_{\mathrm{ij}}=\mathrm{p}_{\mathrm{ii}}$. In other words, the probability of a property staying in a specific state would be no larger than the chance of it changing to any other state. In contrast persistence would imply that the diagonal elements in the transition 
matrix would be greater than the off-diagonal terms. This can be tested using the ChiSquared test, see Dunn and Theisen (1983). The null hypothesis is that there is no persistence and that the diagonal values should be no larger than the off-diagonal entries. 


\section{Estimation of the Transitional Matrix}

To estimate a transition matrix, data are needed that describe the movements of individual properties over time. With such data the transition probabilities can then be estimated by averaging these movements over time. The transitions matrices estimated a number of ways to establish whether the results for the overall data are consistent across time, property types, sectors, size and risk, or are there systematic differences associated across these subgroups which are not reflected in total returns.

The 16 years of annual total returns data for 392 locations were partitioned into four nonoverlapping four/one-year intervals to determine if the performance relationship was consistent over time, or rather, was period specific. Second, the overall data was partitioned into high and low volatility groups to see if returns are differentiated by greater volatility, a result that might be expected if some return/risk trade-off exists. Third the data set was examined to determine if the performance relationship was consistent across sectors, regions and size.

\subsection{The Overall Transition Matrix}

The operation of a Markov chain model of real estate performance depends upon the definition of a set of mutually exclusive and comprehensive states, which are taken as the quartile rankings of the return performance of properties. Two approaches to classifying the quartiles were adopted. The first was to simply rank the properties in each and every year, an approach in line with the work of Young and Graff $(1996,1997)$. This approach however has a major drawback when used in a Markov chain analysis in which there are 
no entrants or leavers since it always implies that the long run performance will be consistent with non-persistent performance, that is, the probability of being in any quartile ranking must be $25 \%$. In order to overcome this problem and to provide a stronger test of persistence in performance another ranking procedure was adopted. In this approach the returns in any one-year was expressed as the deviation from the average of the sample of properties in that year. The resultant values in any one-year could then be considered as abnormal or excess returns for that year. The excess returns for each year were then combined and the total $6272(392 \times 16)$ data points placed into quartile ranks. The subsequent data were then reassigned to the individual years. By this approach it was possible to have more data in some quartile ranks and less data in others in any one year if a property or group of properties displayed persistence in performance over the total sixteen years period. The rationale for this approach stems from the observation that the variation in performance across real estate portfolios within periods is unusually high (as noted by Morrell, 1997). By the transformation used in this study, we are able to model the persistence in superior/inferior performance that would result if the portfolios were bought and held for successive periods.

On the basis of the movements of the 392 'properties', between the quartile rankings in each and every year the values of the transition matrix, which is the basis of the Markov chain model, were derived. This is done for the whole 16 years of data and for 4 subperiods, in order to test for stationarity.

The transition matrix shown below for the whole period.

TABLE 2 ABOUT HERE 
Using equation (2), the Markov system was tested for stationarity. The Chi-squared statistics was $=0.572$ which is insignificantly different from zero at the $99.99 \%$ level. As a consequence the null hypothesis of stationarity was accepted.

The principal diagonal contains fairly large coefficients, which would indicate stability of performance ranking, as suggested by Young and Graff $(1996,1997)$. For example there is a $44 \%$ chances that a 'property' that was ranked in the first quartile in time period $t$ will remain in that quartile in the next period. Similarly a property in the lowest quartile rank in one period has a $46 \%$ chance of remaining in that rank in the following period. The corresponding figures for the second and third quartile are 35\% and 30\% respectively. These probabilities indicate that property in the highest and lowest rankings have a high probability of staying where they are. The test of persistence confirmed this with a Chi-squared value of 864.41. Consequently the null of equality was rejected. However, the existence of a high degree of persistence in total return performance rankings between different time periods cannot be taken as implying market inefficiency. As discussed above in Section 2 such persistence in return performance could be the result of appraisal or valuation smoothing on the part of valuers. In addition to which any persistence in performance is difficult if not impossible to exploit by real estate fund managers due to the high search and transaction costs exhibited in direct real estate markets.

The off-diagonal elements of the transition matrix also provide some worthwhile information not readily available from other types of estimations. For instance the coefficients in Row 1 of Table 2 indicate that approximately $28 \%$ of properties ranked in the first quartile in time period $t$ will enter the second quartile $t+1$. Similarly less than $18 \%$ of the properties in the third performance rank in period $t$ will move up to the first 
rank in $t+1$. Upper off-diagonal probabilities of the matrix are typically higher than the lower off-diagonal probabilities, although only marginally. This suggests that there is more likelihood of performance for the best performing assets to decline more rapidly than for a property to improve its performance.

Taken as a whole the results in the transition matrix above indicate that there is a $73 \%$ chance that a property in the top quartile in one year will achieve above average performance in the next year. On the other hand a property in the lowest quartile has a $73 \%$ chance of exhibiting below average returns in the next period. In contrast properties that appeared in the second quartile in one period have only a 59\% chance of achieving above average returns in the next year. Similarly for properties in the third tier in one year have a 57\% chance of exhibiting below average returns in the next period.

The evidence suggesting two important rules-of-thumb for property fund managers who wish to maximise their performance; (1) Avoid properties with below average performance; (2) Invest in properties in the upper quartile of performance in one year as they have a higher-than-average chance of achieving above average returns next year. In other words a fund manager would be advised to stay with the best and avoid the worst.

\subsection{Sub-Division Transition Matrices}

The data was subsequently divided up in a number of ways to test whether the results were consistent across; sectors, regions, size and volatility. For example, Brown et. al. (1992), Hendricks et al. (1993) and Malkiel (1995) contend that, for mutual funds, persistence is inversely related to total return volatility. Under this interpretation, high- 
risk mutual funds that survive represent instances of mutual fund managers taking a highrisk strategy and succeeding, whereas high-risk funds that took a high-risk strategy and failed, no longer exist. In this context, the remaining mutual funds would be biased towards persistence in performance through time. In other words investors who purchase the best investments on the basis of past performance would in fact be buying volatility.

In an attempt to test for this potential impact, the real estate assets are ranked by their variance of returns over the sixteen-year period, and then partitioned into either a high- or low-risk group, respectively. In other words the properties with a variance above the median are categorised as high-risk, while median and below are categorised as low-risk assets. In a similar fashion the properties were classified into large and small local markets, based on their average market value in 1981. Finally the data was sub-divided into the three sectors; Retail, Office and Industrial and into the four regions; London, the South East, the South West and the North. The results of the analysis, which are all presented in Tables A.1 to A.11 in Appendix 1, suggest that consistency in performance across sectors, regions, size and volatility is not affected by any of these factors.

\subsection{Investment Strategy - Deriving Trading Rules}

Investors who accept the efficient market hypothesis and/or have little forecasting ability are advised to follow a buy-and-hold strategy with a well-diversified portfolio in order to minimise risk and transaction costs. In contrast, investors who believe in the absolute persistence of returns would follow a buy-and-hold strategy concentrated in those assets identified as the winners in one period, in order to maximise returns with minimum transaction costs. The analysis above, however, suggests that there is not an absolute 
persistence in returns from one period but that there is a good deal of persistence in the highest category (quartile 1) from one period to the next. Consequently an investor may be better off by following a more dynamic persistence investment approach and purchase those that were identified as the best in each period and selling those that moved out of the highest category. Such an investment strategy by its nature, although leading to the higher returns than the random or absolute persistent strategy will do so at the cost of high transaction costs, which may eliminate any increase in returns.

The result of the Markov chain analysis in Table 2, however, suggests an alternative, which may achieve both objectives of high returns and low transaction costs. As can be seen although there is only a $44 \%$ chance that a property classified as in the top quartile in one period will maintain that position in the subsequent period there is a $73 \%$ chance that such a property will achieve returns above the median. Similarly a property in the second quartile has a 59\% chance of staying above the median return of the market. Thus an investor may be better off purchasing the top category in period 1 and only selling the individual properties if their returns fall below the median. In other words a movement out of the first quartile to the second is not a signal to sell, as the individual property has a good chance of staying in quartile two or returning to quartile one in the next period. It is only when the property falls below the median that is it enters quartile three or four, should the fund manager sell it. Such a strategy, which may be called a Markov approach, has the advantage of offering higher returns than a random or absolute persistent strategy, but with lower transaction costs. In order to test this contention it was assumed that an investor analysed the quartile rankings of the sampled properties over the four-year period from 1981 to 1984, using the Markov model. The resultant transition matrix in Table 3 was identified, which is almost identical to the result shown in Table 2 over the whole period. 
TABLE 3 ABOUT HERE 


\subsection{Trading Strategy Test Results}

From the forgoing discussion, four investment trading rules can be derived: (1) Efficient markets, a Buy-and-hold strategy; (2) Absolute persistence, a Buy-and-hold strategy formed from properties in the first quartile; (3) Dynamic persistence, based on revising portfolios on the basis of performance in the current period and (4) Markov, dynamic strategy based on the observations about the movement of properties in the transition matrix.

Based on this analysis the four investment strategies identified above were then implemented, over the period 1985 to 1996, based on the ranks in 1984. The results are presented in Table 4.

As is to be expected the Efficient markets strategy achieves returns above that of the Absolute persistence approach. In other words properties do not display absolute persistence. Further the Dynamic persistence strategy achieved the highest returns, but with a portfolio turnover rate above 50\%. The Markov method meanwhile achieved returns only slightly below those of the Dynamic persistence but at a turnover of about half that required by the Dynamic persistence.

\section{TABLE 4 ABOUT HERE}

Although the Markov and the Dynamic persistence strategies out-performed the Efficient markets, and the Absolute persistence strategies, both did so at the cost of a high portfolio turnover rates. In the case of the Dynamic persistence strategy in a 
number of periods portfolio turnover is in excess of $60 \%$. In contrast the Efficient markets and Absolute persistence buy-and-hold strategies have zero turnover rates. Given these results it is obviously important to find out the breakeven transaction costs beyond which it would not be beneficial to engage in the dynamic strategies in order to seek increased returns. By the same token it is important to discover whether the Dynamic persistence strategy can be justified in contrast to the Markov dynamic strategy, given the increase in portfolio turnover.

The percentage breakeven unit transaction cost between any two portfolios is given by the following:

$$
\mathrm{UT}=\frac{\mathrm{MR}_{1}-\mathrm{MR}_{2}}{\mathrm{TO}_{1}-\mathrm{TO}_{2}}
$$

Where MR is the mean returns for each strategy and TO is the portfolio turnover rate (see the appendix for details). Consequently in comparing the dynamic strategies $\left(\mathrm{TO}_{1}\right)$ with the passive portfolios, $\mathrm{TO}_{2}$ is zero. The breakeven percentage transaction costs are presented in Table 5 .

\section{TABLE 5 ABOUT HERE}

As can be seen for the Dynamic persistence strategy in comparison with the Efficient markets or Absolute persistence strategies the unit transaction costs would have to be greater than $6.8 \%$, or $8.2 \%$ respectively to eliminate the difference in returns. The comparable figures for the Markov strategy are $11.8 \%$ and $14.6 \%$. 
In addition in order to justify a switch from the Markov strategy to the Dynamic persistence the transaction costs of the Dynamic persistence strategy would have to be low, in fact using equation (1) above the unit transaction cost would have to be less than 2\%. This suggests that the Markov based strategy is one that can offer high returns that are robust in the face of the relatively high transaction costs faced in the real estate market. Such a result might imply that the property markets are inefficient in the weak form but such an inference would be premature. The difference between these "paper" transactions and actual buying and selling activities may be considerable as many of the transactions would be made in weak market conditions. In practice therefore, it might well turn out to be impossible to achieve the net returns suggested in this exercise.

\section{Conclusion}

For investors, it is compelling to purchase real estate that has performed well in the past and sell real estate that has performed, poorly in prior periods. The viability of such an investment strategy, however, depends upon the stability of the successive period performance relationship over time. Using a large sample of property assets over the period from 1981 to 1996 this study has gained further insight into the strength and stability of the relationship between prior and subsequent period performance of real estate returns in several areas.

First, the observed persistence in performance of real estate returns in other countries was confirmed and appeared to be fairly stable between 1981 and 1996. Second the persistence did not appear to be driven by volatility, and was robust across sectors, regions and unaffected by size variations. 
Using these returns a number of investment strategies were identified and tested over the period from 1985-1996. The results suggest that real estate investors would be better off, in terms of higher returns coupled with a lower turnover rate, by purchasing properties identified as the best in one period and only selling those that fall below the median in the next, rather than concentrating investment in properties from the first quartile. Such a strategy outperforms a random based approach and one assuming absolute persistence in returns, even after transaction costs. We conclude by qualifying our inference that these results imply that the real estate market is inefficient, as it could prove difficult to achieve the returns in the thin markets that often are characteristic of property. 


\section{References}

Anderson, T. W. and Goodman, L. A. (1957) Statistical Inference about Markov Chains, Annals of Mathematics and Statistics, 28, 89-110.

Brown, S. J., Ibbotson, R. G. and Ross, S. A. (1992) Survivorship Bias in Performance Studies, Review of Financial Studies, 5, 4, 553-580.

Brown, S. J. and Goetzmann, W. N. (1995) Performance Persistence, Journal of Finance, 50, 2, 679-698.

Byrne, P. and Lee, S. (1997) Real Estate Portfolio Analysis Under Conditions of NonNormality: The Case of NCREIF, The Journal of Real Estate Portfolio Management, 3, $1,37-46$.

Dunn, P. C. and Theisen, R. D. (1983) How Consistently do Active managers Win? Journal of Portfolio Management, 9, Summer, 47-51.

Fama, E. F. (1970) Efficient Capital Markets: A Review of Theory and Empirical Work, Journal of Finance, 25, 2, 383-417.

Goetzmann, W. N. and Ibbotson, R. G. (1994) Do Winners Repeat'? Patterns in Mutual Fund Return Behavior, Journal of Portfolio Management, 20, 2, 9-17.

Graff, R. A., Harrington, A. and Young, M. S. (1999) Serial Persistence in Disaggregated Australian Real Estate Returns, Journal of Real Estate Portfolio Management, 5, 2, 113-127.

Graff, R. A. and Young, M. S. (1997) Serial Persistence in Equity REIT Returns, Journal of Real Estate Research, 14, 3, 183-214.

Grinblatt, M. and Titman, S. (1989) Mutual Fund Performance: An Analy sis of Quarterly Portfolio Holdings, Journal of Business, 62, 3, 393-416.

Grinblatt, M. and Titman. S. (1992) The Persistence of Mutual Fund Performance. Journal of Finance, 47, 5, 1977-1984.

Hendricks, D., Patel, I., and Zeckhauser, R. (1993) Hot Hands in Mutual Funds: Shortrun Persistence of Relative Performance 1974-1988, Journal of Finance, 40, 1, 93-130.

Investment Property Databank (1998), Local Markets Reports. IPD, Greenland Place, London

Kemeny, J. G. and Snell, J. L. (1960) Finite Markov Chains, D. Van Norstand \& Co., Princeton, New Jersey.

LeRoy, S. F. (1982) Expectations models of asset prices: A survey of theory. Journal of Finance, 37, 1, 185-217. 
Malkiel, B. G. (1995), Returns from Investing in Equity Mutual Funds 1971 to 1991. Journal of Finance, 50, 2, 549-558

Morrell, G. D. (1997) Property Risk and Portfolio Construction, Paper Presented to the Sixth IPD Investment Strategies Conference, 27-28 November, Brighton.

Myer, F. C. N. and Webb J. R. (1990) Are Commercial Real Estate Returns Normally Distributed? Working Paper Cleveland State University, Ohio

Myer, F. C. N. and Webb J. R. (1993) Return Properties of Equity REITs, Common Stocks and Commercial Real Estate: A Comparison. Journal of Real Estate Research, 8, 1, 87-106.

Sivitanides P. S.(1998) A Downside-Risk Approach to Real Estate Portfolio Structuring, Journal of Real Estate Portfolio Management, 4, 2, 159-168.

Young, M. S. and Graff, R. A. (1996) Systematic Behavior in Real Estate Investment Risk: Performance Persistence in NCREIF Returns, Journal of Real Estate Research, 12, 3, 369-381

Young, M. S. and Graff, R. A. (1997) Performance Persistence in Equity Real Estate Returns, Real Estate Finance, 14, 1, 37-42. 
Table 1 : The Number of Data Points in Each Sector/Region

\begin{tabular}{|c|c|c|c|c|}
\hline & \multicolumn{3}{|c|}{$--------S e c t o r s----------$} & \\
\hline Regions & Retail & Office & Industrial & Total \\
\hline London & 27 & 13 & 17 & 57 \\
\hline South East & 61 & 45 & 44 & 150 \\
\hline South and West & 63 & 21 & 19 & 103 \\
\hline Northern & 55 & 14 & 13 & 82 \\
\hline Total & 206 & 93 & 93 & 392 \\
\hline
\end{tabular}

Table 2: Transition Matrix for the Whole Period

\begin{tabular}{|l|c|c|c|c|}
\hline \multicolumn{1}{|c|}{ From / To } & $\begin{array}{c}\text { First } \\
\text { Quartile }\end{array}$ & $\begin{array}{c}\text { Second } \\
\text { Quartile }\end{array}$ & $\begin{array}{c}\text { Third } \\
\text { Quartile }\end{array}$ & $\begin{array}{c}\text { Fourth } \\
\text { Quartile }\end{array}$ \\
\hline First Quartile & $\mathbf{0 . 4 4 4}$ & 0.284 & 0.180 & 0.093 \\
\hline Second Quartile & 0.243 & $\mathbf{0 . 3 4 7}$ & 0.261 & 0.148 \\
\hline Third Quartile & 0.175 & 0.252 & $\mathbf{0 . 2 9 9}$ & 0.274 \\
\hline Fourth Quartile & 0.128 & 0.144 & 0.264 & $\mathbf{0 . 4 6 3}$ \\
\hline
\end{tabular}

Table 3: The Transition Matrices for the First Four Year Sub-Period

\begin{tabular}{|c|c|c|c|c|}
\hline Period 1 & First & Second & Third & Fourth \\
\hline First & $\mathbf{0 . 4 8 8}$ & 0.298 & 0.147 & 0.067 \\
\hline Second & 0.278 & $\mathbf{0 . 3 6 7}$ & 0.247 & 0.108 \\
\hline Third & 0.140 & 0.251 & $\mathbf{0 . 3 2 9}$ & 0.280 \\
\hline Fourth & 0.100 & 0.085 & 0.284 & $\mathbf{0 . 5 3 2}$ \\
\hline
\end{tabular}


Table 4: The Results of the Dynamic and Passive Portfolios from 1985 to 1996

\begin{tabular}{|c|c|c|c|c|c|c|}
\hline \multirow[b]{2}{*}{ Year } & \multicolumn{2}{|c|}{ Buy-and-hold } & \multicolumn{2}{|c|}{ Dynamic } & \multicolumn{2}{|c|}{ Turnover \% } \\
\hline & $E M H$ & \begin{tabular}{|c} 
Absolute \\
Persistenc \\
$e$
\end{tabular} & $\begin{array}{c}\text { Dynamic } \\
\text { Persistence }\end{array}$ & Markov & $\begin{array}{c}\text { Dynamic } \\
\text { Persistence }\end{array}$ & Markov \\
\hline & & & & & & \\
\hline 1985 & 9.33 & 14.52 & 14.52 & 14.52 & & \\
\hline 1986 & 9.64 & 12.69 & 14.22 & 13.35 & 0.50 & 0.18 \\
\hline 1987 & 20.41 & 19.82 & 24.26 & 23.26 & 0.49 & 0.22 \\
\hline 1988 & 31.02 & 26.26 & 36.99 & 35.18 & 0.57 & 0.34 \\
\hline 1989 & 18.37 & 11.18 & 26.81 & 25.15 & 0.59 & 0.30 \\
\hline 1990 & -5.96 & -8.57 & -1.58 & -2.49 & 0.51 & 0.17 \\
\hline 1991 & 3.78 & 2.63 & 8.16 & 7.28 & 0.52 & 0.21 \\
\hline 1992 & 1.34 & 2.30 & 5.02 & 5.20 & 0.51 & 0.29 \\
\hline 1993 & 19.32 & 18.99 & 21.95 & 21.61 & 0.53 & 0.27 \\
\hline 1994 & 10.50 & 9.49 & 11.50 & 12.33 & 0.67 & 0.34 \\
\hline 1995 & 1.41 & 1.20 & 2.55 & 2.32 & 0.69 & 0.39 \\
\hline 1996 & 7.77 & 6.91 & 8.85 & 8.72 & 0.63 & 0.35 \\
\hline & & & & & \multicolumn{2}{|c|}{ Average } \\
\hline & & & & & \multicolumn{2}{|c|}{ Turnover } \\
\hline $\begin{array}{l}\text { Geomet } \\
\text { Mean }\end{array}$ & 10.15 & 9.39 & 13.95 & 13.41 & 0.57 & 0.28 \\
\hline
\end{tabular}

Table 5: Breakeven Percentage Transaction Costs

\begin{tabular}{|c|c|c|}
\hline & \multicolumn{2}{|c|}{ Dynamic } \\
\hline & $\begin{array}{c}\text { Dynamic } \\
\text { Persistence }\end{array}$ & Markov \\
\hline Efficient markets & $\mathbf{6 . 8}$ & $\mathbf{1 1 . 8}$ \\
\hline Absolute & $\mathbf{8 . 2}$ & $\mathbf{1 4 . 6}$ \\
\hline
\end{tabular}




\section{Appendix 1: Transition Matrices}

\section{$\underline{\text { High/Low Risk Matrices }}$}

Table A.1: Low Risk Transition Matrix

\begin{tabular}{|l|l|l|l|}
\hline 0.4261 & 0.2810 & 0.1784 & 0.1145 \\
\hline 0.2486 & 0.3076 & 0.2795 & 0.1643 \\
\hline 0.1867 & 0.2545 & 0.2835 & 0.2752 \\
\hline 0.1180 & 0.1790 & 0.2878 & 0.4151 \\
\hline
\end{tabular}

Stationary test $=1.67$ and Persistence test $=370.38$

Table A.2: High Risk Transition Matrix

\begin{tabular}{|l|l|l|l|}
\hline 0.4368 & 0.2855 & 0.1750 & 0.1026 \\
\hline 0.2525 & 0.3529 & 0.2468 & 0.1478 \\
\hline 0.1964 & 0.2437 & 0.2939 & 0.2660 \\
\hline 0.1137 & 0.1503 & 0.2758 & 0.4601 \\
\hline
\end{tabular}

Stationary test $=3.31$ and Persistence test $=490.82$

\section{$\underline{\text { Large Value/Small Value Matrices }}$}

Table A.3: Large Value Towns Transition Matrix

\begin{tabular}{|l|l|l|l|}
\hline 0.4280 & 0.2773 & 0.1773 & 0.1173 \\
\hline 0.2504 & 0.3281 & 0.2574 & 0.1641 \\
\hline 0.1906 & 0.2707 & 0.2831 & 0.2555 \\
\hline 0.1331 & 0.1331 & 0.2754 & 0.4585 \\
\hline
\end{tabular}

Stationary test $=2.39$ and Persistence test $=435.92$

Table A.4: Small Value Towns Transition Matrix

\begin{tabular}{|l|l|l|l|}
\hline 0.3876 & 0.2698 & 0.1971 & 0.1455 \\
\hline 0.2496 & 0.3189 & 0.2655 & 0.1659 \\
\hline 0.1965 & 0.2578 & 0.2892 & 0.2565 \\
\hline 0.1451 & 0.1834 & 0.2731 & 0.3984 \\
\hline
\end{tabular}

Stationary test $=1.86$ and Persistence test $=261.75$ 


\section{$\underline{\text { Sector Transition Matrices }}$}

Table A.5: Retail Sector Transition Matrix

\begin{tabular}{|l|l|l|l|}
\hline 0.3790 & 0.2738 & 0.2028 & 0.1445 \\
\hline 0.2470 & 0.3063 & 0.2591 & 0.1876 \\
\hline 0.2078 & 0.2471 & 0.2993 & 0.2458 \\
\hline 0.1447 & 0.2038 & 0.2629 & 0.3887 \\
\hline
\end{tabular}

Stationary test $=1.17$ and Persistence test $=234.41$

Table A.6: Office Sector Transition Matrix

\begin{tabular}{|l|l|l|l|}
\hline 0.4185 & 0.2837 & 0.1517 & 0.1461 \\
\hline 0.2515 & 0.3402 & 0.2456 & 0.1627 \\
\hline 0.1919 & 0.2326 & 0.3169 & 0.2587 \\
\hline 0.1345 & 0.1401 & 0.2941 & 0.4314 \\
\hline
\end{tabular}

Stationary test $=2.22$ and Persistence test $=189.96$

Table A.7: Industrial Sector Transition Matrix

\begin{tabular}{|l|l|l|l|}
\hline 0.3906 & 0.2299 & 0.1773 & 0.2022 \\
\hline 0.2145 & 0.2931 & 0.2568 & 0.2356 \\
\hline 0.2006 & 0.2537 & 0.2861 & 0.2596 \\
\hline 0.1923 & 0.2225 & 0.2967 & 0.2885 \\
\hline
\end{tabular}

Stationary test $=2.62$ and Persistence test $=61.00$ 


\section{$\underline{\text { Regional Transition Matrices }}$}

Table A.8: London Region Transition Matrix

\begin{tabular}{|l|l|l|l|}
\hline 0.4751 & 0.2805 & 0.1176 & 0.1267 \\
\hline 0.2609 & 0.3623 & 0.2512 & 0.1256 \\
\hline 0.1845 & 0.2184 & 0.3447 & 0.2524 \\
\hline 0.0950 & 0.1403 & 0.2851 & 0.4796 \\
\hline
\end{tabular}

Stationary test $=4.60$ and Persistence test $=189.23$

Table A.9: South East Region Transition Matrix

\begin{tabular}{|l|l|l|l|}
\hline 0.4131 & 0.2685 & 0.1910 & 0.1274 \\
\hline 0.2547 & 0.3302 & 0.2491 & 0.1660 \\
\hline 0.1800 & 0.2852 & 0.2799 & 0.2549 \\
\hline 0.1453 & 0.1367 & 0.2907 & 0.4273 \\
\hline
\end{tabular}

Stationary test $=3.86$ and Persistence test $=281.63$

Table A.10: South \& West Region Transition Matrix

\begin{tabular}{|l|l|l|l|}
\hline 0.4677 & 0.2612 & 0.1891 & 0.0821 \\
\hline 0.2348 & 0.3398 & 0.3011 & 0.1243 \\
\hline 0.1618 & 0.2732 & 0.2812 & 0.2838 \\
\hline 0.1089 & 0.1708 & 0.2500 & 0.4703 \\
\hline
\end{tabular}

Stationary test $=3.65$ and Persistence test $=302.81$

Table A.11: Northern Region Transition Matrix

\begin{tabular}{|l|l|l|l|}
\hline 0.4441 & 0.2875 & 0.1725 & 0.0958 \\
\hline 0.2567 & 0.3333 & 0.2567 & 0.1533 \\
\hline 0.2007 & 0.2274 & 0.3244 & 0.2475 \\
\hline 0.0912 & 0.1792 & 0.2516 & 0.4780 \\
\hline
\end{tabular}

Stationary test $=2.71$ and Persistence test $=220.56$ 


\section{Appendix 2: Breakeven Transaction Costs}

The Transaction Costs (TC) expressed as a proportion of the average value of a trade, equals the Unit Transaction (UT) times the portfolio Turnover (TO) expressed as a proportion. That is

$$
\mathrm{TC}=\mathrm{UTxTO}
$$

The net return of a portfolio $\left(\mathrm{R}_{\mathrm{P}}\right)$ after transaction costs is:

$$
\mathrm{R}_{\mathrm{P}}=\mathrm{MR}-\mathrm{TC}
$$

where MR is the gross return of the portfolio and TC is as defined above. Therefore, the difference in return between any two portfolios after transaction is:

$$
\mathrm{D}=\mathrm{MR}_{1}-\mathrm{TC}_{1}-\mathrm{MR}_{2}-\mathrm{TC}_{2}
$$

or

$$
\mathrm{D}=\mathrm{MR}_{1}-\mathrm{UT}_{1} \times \mathrm{TO}_{1}-\mathrm{MR}_{2}-\mathrm{UT}_{2} \mathrm{XTO}_{2}
$$

But if we assume the unit transaction costs are the same for both portfolios the breakeven position will be given by setting D equal to zero and solving for UT, that is

$$
\mathrm{UT}=\frac{\mathrm{MR}_{1}-\mathrm{MR}_{2}}{\mathrm{TO}_{1}-\mathrm{TO}_{2}}
$$

